\title{
CONF-941115--5
}

Note: This is a preprint of a paper being submitted for publication. Contents of this paper should not be quoted nor referred to without permission of the author(s).

To be submitted to Fall 1994 Materials Research Society Meeting, Symposium F: Microcrystalline and Nanocrystalline Semiconductors, ed. by L. Brus, R. W. Collins, M. Hirose, and F. Koch.

\section{COMPOUND SEMICONDUCTOR NANOCRYSTALS FORMED BY SEQUENTIAL ION IMPLANTATION}

C. W. WHITE, J. D. BUDAI, J. G. ZHU,

S. P. WITHROW, R. A. ZUHR, and Y. CHEN

Oak Ridge National Laboratory

Oak Ridge, TN

D. M. HEMBREE, JR

The Y-12 Plant

Oak Ridge, TN

R. H. MAGRUDER

Vanderbilt University

Nashville, TN

D. O. HENDERSON

Fisk University

Nashville, TN

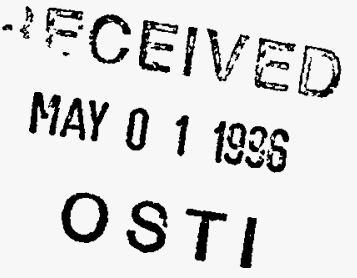

"The submitted manuscript has been authored by a contractor of the U.S. Government under contret No DE-AC05. 840R21400. Accordingly, the U.S. Government retains nonexelusive, royalty-free license to publish or reproduce the published form of this contribution, or allow others to do so, for U.S. Govemment purposes."

Prepared by the Oak Ridge National Laboratory Oak Ridge, Tennessee 37831 managed by

MARTIN MARIETTA ENERGY SYSTEMS, INC. for the U.S. DEPARTMENT OF ENERGY under contract DE-AC05-84OR21400

November 1994

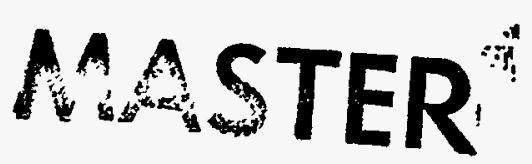




\title{
COMPOUND SEMICONDUCTOR NANOCRYSTALS FORMED BY SEQUENTIAL ION IMPLANTATION
}

\author{
C. W. WHITE,* J. D. BUDAI,* J. G. ZHU,* S. P. WITHROW,* R. A. ZUHR,* Y. CHEN,* \\ D. M. HEMBREE, Jr., ** R. H. MAGRUDER, $\ddagger$ AND D. O. HENDERSON $\ddagger \ddagger$
}

*Oak Ridge National Laboratory, P. O. Box 2008, Oak Ridge, TN 37831-6057

**The Y-12 Plant, P. O. Box 2009, Oak Ridge, TN 37831

\$Vanderbilt University, 24th Avenue S and Garland, Nashville, TN 37212

+†Fisk University, Physics Department, Nashville, TN 37208

\begin{abstract}
Ion implantation and thermal processing have been used to synthesize compound semiconductor nanocrystals ( $\mathrm{SiGe}, \mathrm{GaAs}$, and $\mathrm{CdSe}$ ) in both $\mathrm{SiO}_{2}$ and (0001) $\mathrm{Al}_{2} \mathrm{O}_{3}$. Equal doses of each constituent are implanted sequentially at energies chosen to give an overlap of the profiles. Subsequent annealing results in precipitation and the formation of compound nanocrystals. In $\mathrm{SiO}_{2}$ substrates, nanocrystals are nearly spherical and randomly oriented. In $\mathrm{Al}_{2} \mathrm{O}_{3}$, nanocrystals exhibit strong orientation both in-plane and along the surface normal.
\end{abstract}

\section{INTRODUCTION}

In recent years, considerable interest has been generated in nanometer size semiconductor nanocrystals which have unique properties resulting from quantum confinement in systems of reduced linear dimensions. Much of this interest occurs because of the possibility for fabricating optoelectronic devices and optical amplifiers. The elemental semiconductor nanocrystals Si and Ge exhibit room-temperature visible-light emission at energies greater than the bandgap of the bulk semiconductor. ${ }^{1-4}$ Intense light emission is also observed in the visible region from porous $\mathrm{Si}^{5}$ Compound semiconductor nanocrystals can have nearly discrete electronic states 6 and exhibit very large third-order nonlinear optical properties and fast relaxation times, ${ }^{7}$ making them very interesting for possible applications in optical switching devices. Because of the very unusual properties associated with semiconductor nanocrystals, numerous techniques are being used to synthesize such nanocrystaline materials. These include cosputtering (to form $\mathrm{Ge}^{2}, \mathrm{Si}^{8}$, and II-VI compound semiconductor 9,10 nanocrystals in $\mathrm{SiO}_{2}$ ), plasma decomposition of $\mathrm{SiH}_{4}$ to form Si nanocrystals, ${ }^{1}$ organometallic reaction to form compound semiconductor nanocrystals, 11 etc.

Ion implantation is ideally suited for the fabrication of very high densities of nanocrystals in the near-surface region of a wide variety of materials and this method has been used to create $\mathrm{Si}$ or Ge nanocrystals in $\mathrm{SiO}_{2} .{ }^{12,13}$ We are exploring the use of ion implantation to form a wide variety of nanocrystals in several insulating materials. We have demonstrated ${ }^{14,15}$ that implantation can be used to synthesize $\mathrm{Si}$ and $\mathrm{Ge}$ nanocrystals in both $\mathrm{SiO}_{2}$ and $\mathrm{Al}_{2} \mathrm{O}_{3}$. In this paper, we report the synthesis of compound semiconductor nanocrystals in $\mathrm{SiO}_{2}$ and $\mathrm{Al}_{2} \mathrm{O}_{3}$ by sequential implantation of the individual constituents of the compound, at energies chosen to give an overlap of the profiles. If the individual constituents are insoluble in the matrix, and if they have a chemical affinity for each other, then precipitation and compound formation can occur during subsequent annealing. We show results for SiGe, GaAs, and CdSe in the two substrates. This is the first report, to our knowledge, of the use of sequential implantation to form compound semiconductor nanoparticles. Previously, sequential implantation of metal ions was used to form ternary metal silicides in silicon. ${ }^{16}$ In addition, the alloying of metal ions sequentially implanted into $\mathrm{SiO}_{2}$ has been inferred from shifts in the wavelength of the surface plasmon resonance. ${ }^{17}$ 


\section{EXPERIMENTAL DETAILS}

The individual constituents of the desired compound semiconductor were implanted sequentially at the proper stoichiometric ratio. Substrates used were fused silica, thermally grown $\mathrm{SiO}_{2}$ films $\left(\sim 8000 \AA\right.$ thick) on (001) $\mathrm{Si}$, and (0001) $\mathrm{Al}_{2} \mathrm{O}_{3}$ crystals. Energies were chosen for each ion specie to ensure an overlap of the profiles. Doses were in the range of $3 \times 10^{16} / \mathrm{cm}^{2}$ to $3 \times 10^{17} / \mathrm{cm}^{2}$ for each specie. Substrate temperatures ranged from room temperature to $650^{\circ} \mathrm{C}$. Following implantation, annealing was carried out in a reducing atmosphere $\left(\mathrm{Ar}+4 \% \mathrm{H}_{2}\right)$ for $1 \mathrm{~h}$ at temperatures in the range of $600^{\circ} \mathrm{C}$ to $1100^{\circ} \mathrm{C}$. Sample characterization was carried out using x-ray diffraction ( $\mathrm{CuK} \alpha_{1}$ radiation), cross-section transmission electron microscopy (TEM), Raman spectroscopy (488 nm excitation) as well as Rutherford backscattering-ion channeling to monitor the impurity depth profile and crystallinity in the near-surface region. Optical properties of selected nanocrystal composites were determined using visible, UV, and infrared absorption as well as photoluminsescence measurements.

\section{RESULTS AND DISCUSSION}

Figure 1 shows a cross-section TEM micrograph and particle size distribution measured for $\mathrm{SiGe}$ nanocrystals in $\mathrm{SiO}_{2}$. In this case, $\mathrm{Si}$ ions $(215 \mathrm{keV})$ and $\mathrm{Ge}$ ions $(500 \mathrm{keV})$ were implanted into $\mathrm{SiO}_{2}$ to give an impurity profile peaked at a depth of $\sim 3100 \AA$ with a full width at half maximum of $\sim 2500 \AA$ for each constituent. Following implantation, the sample was annealed at $1000^{\circ} \mathrm{C}$ to induce precipitation and nanocrystal formation. X-ray diffraction showed strong diffraction lines characteristic of randomly oriented, diamond cubic SiGe, and the Raman spectrum from this sample was similar to that measured from bulk SiGe. These techniques identify the nanoparticles as a SiGe alloy, but $\mathrm{Si}$ and $\mathrm{Ge}$ are completely soluble in each other, and there is almost certainly a range of compositions in the alloy. The lack of $\mathrm{x}$-ray diffraction lines and Raman lines characteristic of pure Si or pure Ge shows that there are few, if any, precipitates of the pure phase of each constituent. The TEM results show the individual SiGe nanocrystals. The size distribution is peaked at $\sim 50 \AA$ with a few precipitates having diameters as large as $200 \AA$. It should be possible to produce smaller nanocrystals and a narrower distribution by using lower doses or lower annealing temperatures as demonstrated in our work ${ }^{15}$ on $\mathrm{Ge}$ nanocrystals in $\mathrm{SiO}_{2}$. SiGe nanocrystals have also been produced in $\mathrm{AI}_{2} \mathrm{O}_{3}$ by the implantation of $\mathrm{Si}$ and $\mathrm{Ge}$, followed by annealing. In that case, the nanocrystals are oriented preferentially with their (111) planes parallel to (0001) $\mathrm{Al}_{2} \mathrm{O}_{3}$ planes. These nanocrystals also exhibit strong in-plane alignment. Details will be published separately.
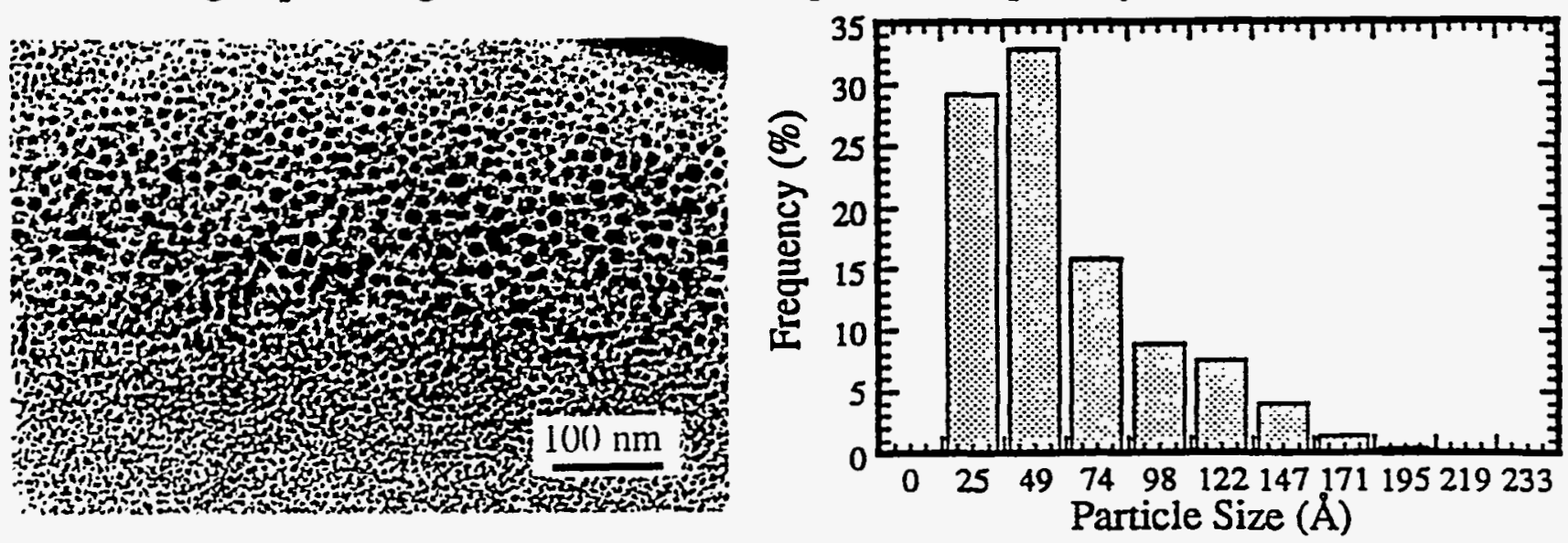

Fig. 1. (left) $\mathrm{SiGe}$ nanocrystals in $\mathrm{SiO}_{2}$. Equal doses $\left(3 \times 10^{17} / \mathrm{cm}^{2}\right)$ of each constituent were implanted at energies chosen to give an overlap of the profile. (right) Measured size distribution for the SiGe nanocrystals. 


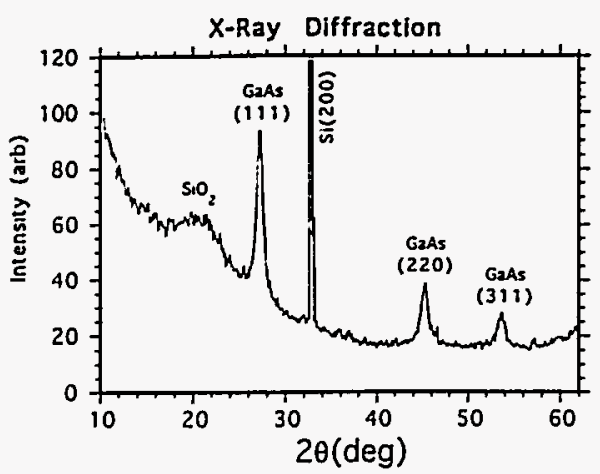

Fig. 2. X-ray diffraction characterization of $\mathrm{GaAs}$ nanocrystals in $\mathrm{SiO}_{2}$. Equal doses $\left(1.5 \times 10^{17} / \mathrm{cm}^{2}\right)$ of $\mathrm{Ga}$ (at $470 \mathrm{keV}$ ) and As (at $500 \mathrm{keV}$ ) were implanted into an $\mathrm{SiO}_{2} / \mathrm{Si}$ substrate. Annealing was carried out at $1000^{\circ} \mathrm{C}(1 \mathrm{~h})$.

Nanocrystals of $\mathrm{GaAs}$ have also been synthesized in $\mathrm{SiO}_{2}$ and $\mathrm{Al}_{2} \mathrm{O}_{3}$ by sequential implantation of equal doses of $\mathrm{Ga}$ and $\mathrm{As}$, followed by thermal annealing to induce precipitation and compound formation. Figure 2 shows $\mathrm{x}$-ray diffraction results for the case of $\mathrm{GaAs}$ nanocrystals in $\mathrm{SiO}_{2}$. The $\theta-2 \theta$ scan in Fig. 2 shows the expected scattering from amorphous $\mathrm{SiO}_{2}$ and a relatively strong multiple-scattering $\mathrm{Si}(200)$ peak from the underlying Si substrate. In addition, there are strong peaks which are identified as arising from diamond cubic GaAs. The intensities of these reflections are consistent with those for a randomly oriented powder. The width of these peaks provides information on the volume-weighted correlation length (size of coherently diffracting domains) which, in this case, is of order $140 \AA$ in the direction of the surface normal. TEM results from this same sample show that the GaAs nanoparticles are nearly spherical and randomly oriented. The average size is $\sim 100 \AA$ diameter, with a few extending up to $\sim 250 \AA$ in diameter. Infrared reflectance measurements on similar samples show a welldefined peak at $280 \mathrm{~cm}^{-1}$ which we believe corresponds to the longitudinal optical mode of GaAs in these nanoparticles since it is close to that measured by others for bulk and epitaxial GaAs films. 19

Figure 3 shows $x$-ray diffraction results for the case of GaAs nanocrystals in (0001) $\mathrm{Al}_{2} \mathrm{O}_{3}$. The $\theta-2 \theta$ scan (top) along the $\mathrm{c}$ axis of $\mathrm{Al}_{2} \mathrm{O}_{3}$ shows the expected strong diffraction from (0001) planes of $\mathrm{Al}_{2} \mathrm{O}_{3}$. In addition, there are strong diffraction peaks from (111) GaAs planes, as well as (weaker) diffraction from (110) GaAs. The intensity ratios show that the GaAs nanoparticles have a tendency to orient with their (111) planes parallel to the (0001) planes of $\mathrm{Al}_{2} \mathrm{O}_{3}$. The width of the GaAs (111) peak suggests a GaAs grain size of $\sim 370 \AA$ along the surface normal. The (111) oriented GaAs domains also exhibit strong in-plane alignment as shown by the $\phi$ scans through the $\{200\}$ reflections. The $\phi$ scan results show that there are several possible in-plane orientations for the GaAs domains.

CdSe nanocrystals have also been synthesized in $\mathrm{SiO}_{2}$ and $\mathrm{Al}_{2} \mathrm{O}_{3}$. Figure 4 shows a TEM image from CdSe nanocrystals in $\mathrm{SiO}_{2}$. In this sample, the CdSe nanoparticles are nearly spherical, randomly oriented, and have an average size of $\sim 50 \AA$. A few extend to diameters of $100 \AA$.
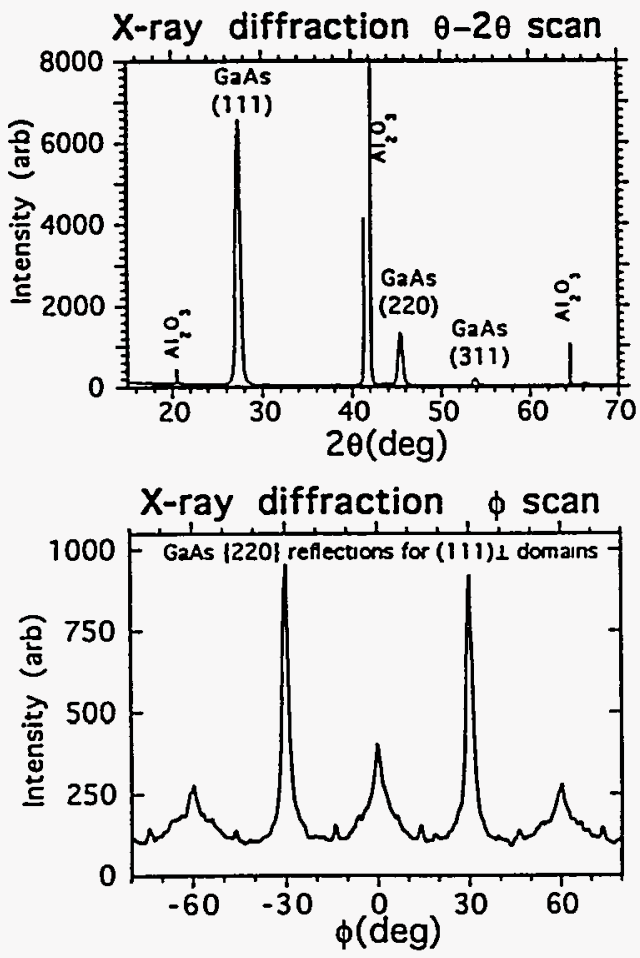

Fig. 3. X-ray diffraction from GaAs nanocrystals in (0001) $\mathrm{Al}_{2} \mathrm{O}_{3}$. Equal doses $1 \times 10^{17} / \mathrm{cm}^{2}$ ) of Ga (at $470 \mathrm{keV}$ ) and As (at $500 \mathrm{keV}$ ) were implanted, and the sample was annealed at $1100^{\circ} \mathrm{C} / 1 \mathrm{~h}$. 


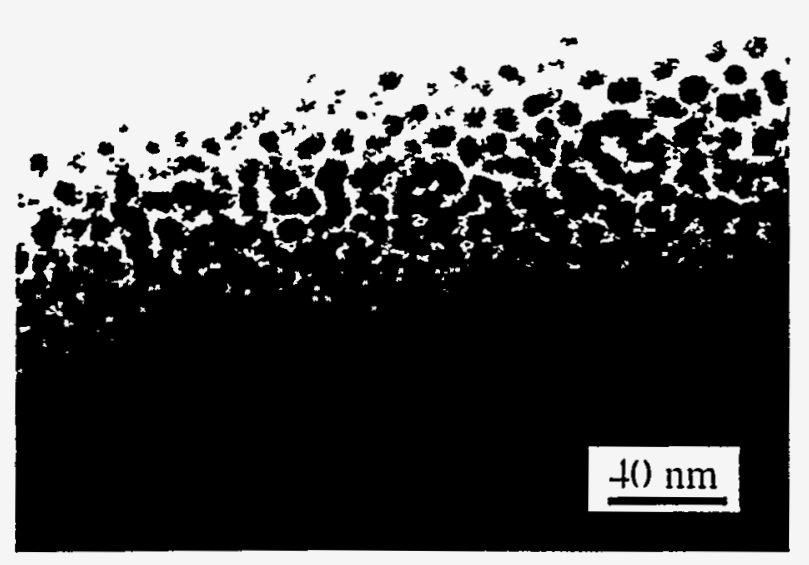

Fig. 4. CdSe nanocrystals in $\mathrm{SiO}_{2}$. Equal doses $\left(1 \times 10^{17} / \mathrm{cm}^{2}\right)$ of $\mathrm{Cd}($ at $450 \mathrm{keV})$ and $\mathrm{Se}($ at $330 \mathrm{keV})$ were implanted and the sample was annealed at $1000^{\circ} \mathrm{C} / 1 \mathrm{~h}$.

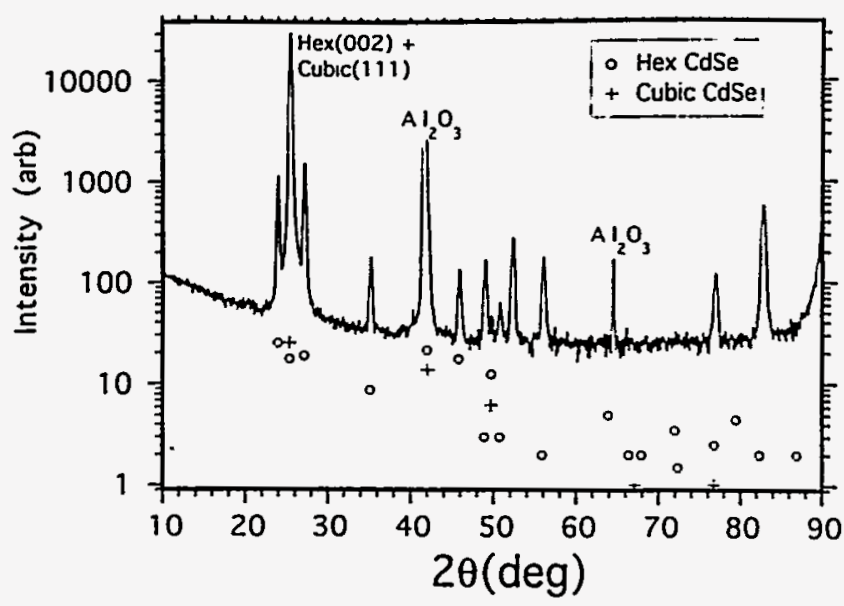

Fig. 5. X-ray diffraction from CdSe nanocrystals in (0001) $\mathrm{Al}_{2} \mathrm{O}_{3}$. Equal doses $\left(4.3 \times 10^{16} / \mathrm{cm}^{2}\right)$ of $\mathrm{Cd}(450 \mathrm{keV})$ and $\mathrm{Se}$ $(330 \mathrm{keV})$ were implanted at a substrate temperature of $600^{\circ} \mathrm{C}$. The sample was annealed at $1000^{\circ} \mathrm{C} / 1 \mathrm{~h}$.

Equilibrium CdSe exists in one of two structures, cubic and hexagonal, depending on pressure. The $\mathrm{x}$-ray diffraction results from this sample reveal the presence of hexagonal CdSe, similar to results ${ }^{18}$ reported for $\mathrm{CdSe}$ nanocrystals synthesized in $\mathrm{SiO}_{2}$ by cosputtering. However, because of overlapping diffraction peaks, we cannot rule out the possibility that a small amount of cubic CdSe is also present in the implanted samples.

Figure 5 shows $\mathrm{x}$-ray diffraction results demonstrating that oriented CdSe nanocrystals have been formed in $\mathrm{Al}_{2} \mathrm{O}_{3}$ by sequential implantation followed by annealing. The $\theta-2 \theta$ scans along the $c$ axis show the expected scattering from $\mathrm{Al}_{2} \mathrm{O}_{3}$, along with numerous peaks which are consistent with those expected from CdSe. The expected position and relative intensities (from the powder diffraction files) of peaks arising from hexagonal and cubic CdSe are shown also in Fig. 5. From these data, the nanocrystals are identified as hexagonal, although there may be small amounts of the cubic phase present. The hexagonal CdSe (002) planes are strongly oriented parallel to the (0001) planes of $\mathrm{Al}_{2} \mathrm{O}_{3}$, and $\phi$ scans for these domains exhibit strong inplane sixfold alignment. (Relative intensities of the lines in Fig. 5 will not agree with the predictions of power diffraction lines because these nanocrystals are strongy oriented.) Figure 6 shows a TEM image for this sample. This micrograph shows one isolated and several overlapping hexagonal shaped CdSe nanocrystals. Dimensions parallel to the $c$

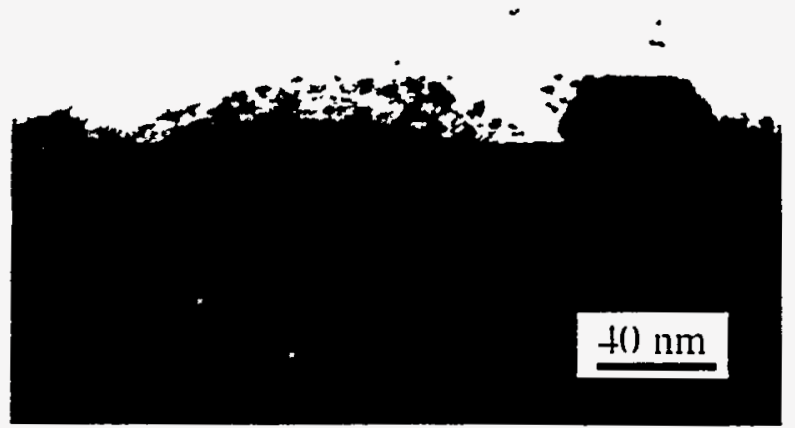
planes of $\mathrm{Al}_{2} \mathrm{O}_{3}$ are several hundred angstroms, and along the $c$ axis are $\sim 200 \AA$, consistent with the widths of the diffraction lines. The CdSe nanocrystals in this sample are mostly in the hexagonal phase. However, CdSe nanoparticles have been synthesized also in the cubic phase using different implantation and annealing conditions in $\mathrm{Al}_{2} \mathrm{O}_{3}$. Details will be published separately.

Fig. 6. CdSe nanocrystals in (0001) $\mathrm{Al}_{2} \mathrm{O}_{3}$. This is the same sample as that of Fig. 5. 

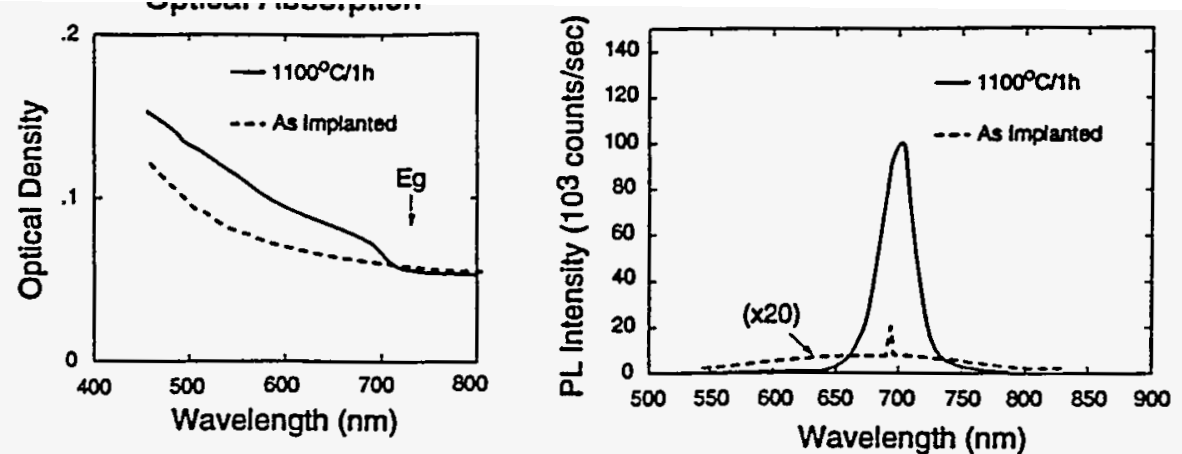

Fig. 7. Optical properties of $\mathrm{CdSe}$ nanocrystals in (0001) $\mathrm{Al}_{2} \mathrm{O}_{3}$. This is the same sample as that of Fig. 5.

Experiments to determine the optical properties of these compound semiconductor nanocrystal composites have just been initiated. One result is shown in Fig. 7 for the CdSe nanocrystals in $\mathrm{Al}_{2} \mathrm{O}_{3}$. The optical absorption results show a blue shift of $-0.1 \mathrm{eV}$ relative to the bandgap $(1.7 \mathrm{eV})$ of bulk CdSe. Such a shift is consistent with the absorption results reported in ref. 11 for the large CdSe nanoparticles ( $\sim 115 \AA$ diameter) in that study. In addition, intense band edge photoluminescence is observed as shown in Fig. 7b. Both the shift in optical absorption and the wavelength of the band edge luminescence should be strong functions of the nanocrystal size. Experiments to demonstrate this behavior are in progress.

\section{CONCLUSIONS}

Ion implantation followed by thermal processing has been used to synthesize a variety of compound semiconductor nanocrystals in both $\mathrm{SiO}_{2}$ and $\mathrm{Al}_{2} \mathrm{O}_{3}$. Supersaturated solutions of individual constituents are created by sequential implantation at energies chosen to give an overlap of the profiles and at doses chosen to give the desired stoichiometry. If both implanted constituents are insoluble in the matrix, and if the constituents have a chemical affinity for each other, then thermal annealing gives rise to precipitation and the formation of compounds. Results are demonstrated for the case of SiGe, GaAs, and CdSe in the two matrices. In $\mathrm{SiO}_{2}$, the nanocrystais are nearly spherical, randomly oriented, and have diameters ranging from 20 $300 \AA$. In $\mathrm{Al}_{2} \mathrm{O}_{3}$, nanocrystals are strongly oriented with the matrix. It should be possible to synthesize a very broad range of nanocrystals in a wide variety of host materials by using the sequential implantation method.

\section{ACKNOWLEDGMENTS}

Research at ORNL was supported partly by the Division of Materials Sciences, U.S. Department of Energy, under contract DE-AC05-840R21400 with Martin Marietta Energy Systems, Inc. and partly through the ORISE Postdoctoral Program. Research at Vanderbilt was supported by Army Research Office grant DAAH04-93-G-0123. Research at Fisk University was supported by DOE through grant DE-FG05-94ER45521.

\section{REFERENCES}

1. H. Takagi, H. Ogawa, Y. Yamazaki, A. Ishizaki, and T. Nakagiri, Appl. Phys. Lett. 56, 2379 (1990).

2. Y. Maeda, N. Tsukamoto, Y. Yazawa, Y. Kanemitsu, and Y. Masumoto, Appl. Phys. Lett. 59, 3168 (1991).

3. W. L. Wilson, P. F. Szajowski, and L. E. Brus, Science 262, 1242 (1993). 
4. L. Brus, J. Phys. Chem. 98, 3575 (1994).

5. L. T. Canhan, Appl. Phys. Lett. 57, 1046 (1990).

6. L. Brus, Appl. Phys. A 53, 465 (1991).

7. R. K. Jain and R. C. Lind, J. Opt. Soc. Am. 73, 647 (1983).

8. S. Hayashi, T. Nagareda, Y. Kanzawa, and K. Yamamoto, Jpn. J. Appl. Phys. 32, 3840 (1993).

9. K. Tsunetomo, H. Nasu, H. Kitayama, A. Kawabucki, Y. Osaka, and K. Takiyama, Jpn.J. Appl. Phys. 28, 1928 (1989).

10. B. G. Potter and J. H. Simmons, J. Appl. Phys. 68, 1218 (1990).

11. C. B. Murray, D. J. Norris, and M. G. Bawendi, J. Am. Chem. Soc. 115, 8706 (1993).

12. H. Atwater et. al., Mat. Res. Soc. Sym. Proc. 316, 409 (1994).

13. T. Shimizu-Iwayama, K. Fujita, S. Nakao, K. Saitoh, T. Fujita, and N. Itoh, J. Appl. Phys. 75, 7779 (1994).

14. C. W. White et al., Mat. Res. Soc. Sym. Proc. 316, 487 (1994).

15. J. G. Zhu et al., these proceedings; J D. Budai et al., these proceedings.

16. Z. Tan, F. Namavar, S. M. Heald, and J. Budnick, Appl. Phys. Lett. 63, 791 (1993).

17. R. H. Magruder, J. E. Wittig, and R. A. Zuhr, J. Non Cryst. Solids 163, 162 (1993); R. A. Zuhr, R. H. Magruder, T. A. Anderson, and J. E. Wittig, Mat. Res. Soc. Sym. Proc. 316, 457 (1994).

18. K. Tsunetomo, A. Kawabuchi, H. Kitayama, Y. Osaka, and H. Nasu, Jpn. J. Appl. Phys. 29, 2481 (1990).

19. R. T. Holm, J. W. Gibson, and E. D. Palik, J. Appl. Phys. 48, 212 (1976).

\section{DISCLAIMER}

This report was prepared as an account of work sponsored by an agency of the United States Government. Neither the United States Government nor any agency thereof, nor any of their Government. Neither the United States Government nor any agency thereor, nor any or thes bility for the accuracy, completeness, or usefulness of any information, apparatus, product, or process disclosed, or represents that its use would not infringe privately owned rights. Reference herein to any specific commercial product, process, or service by trade name, trademark, manufacturer, or otherwise does not necessarily constitute or imply its endorsement, recommendation, or favoring by the United States Government or any agency thereof. The views and opinions of authors expressed herein do not necessarily state or reflect those of the United States Government or any agency thereof. 